REVIEW

\title{
Treatment of respiratory failure in COPD
}

\author{
Stephan Budweiser ${ }^{1}$ \\ Rudolf A Jörres ${ }^{2}$ \\ Michael Pfeifer ${ }^{1,3}$ \\ 'Center for Pneumology, Hospital \\ Donaustauf, Donaustauf, Germany; \\ ${ }^{2}$ Institute and Outpatient Clinic \\ for Occupational, Social and \\ Environmental Medicine, \\ Ludwig-Maximilians-University, Munich, \\ Germany; ${ }^{3}$ Department of Internal \\ Medicine II, Division of Respirology, \\ University of Regensburg, Regensburg, \\ Germany
}

\begin{abstract}
Patients with advanced COPD and acute or chronic respiratory failure are at high risk for death. Beyond pharmacological treatment, supplemental oxygen and mechanical ventilation are major treatment options. This review describes the physiological concepts underlying respiratory failure and its therapy, as well as important treatment outcomes. The rationale for the controlled supply of oxygen in acute hypoxic respiratory failure is undisputed. There is also a clear survival benefit from long-term oxygen therapy in patients with chronic hypoxia, while in mild, nocturnal, or exercise-induced hypoxemia such long-term benefits appear questionable. Furthermore, much evidence supports the use of non-invasive positive pressure ventilation in acute hypercapnic respiratory failure. It application reduces intubation and mortality rates, and the duration of intensive care unit or hospital stays, particularly in the presence of mild to moderate respiratory acidosis. COPD with chronic hypercapnic respiratory failure became a major indication for domiciliary mechanical ventilation, based on pathophysiological reasoning and on data regarding symptoms and quality of life. Still, however, its relevance for long-term survival has to be substantiated in prospective controlled studies. Such studies might preferentially recruit patients with repeated hypercapnic decompensation or a high risk for death, while ensuring effective ventilation and the patients' adherence to therapy.
\end{abstract}

Keywords: respiratory failure, COPD, mechanical ventilation, non-invasive ventilation long-term oxygen therapy, chronic hypercapnic respiratory failure, oxygen

\section{Introduction}

Chronic obstructive pulmonary disease (COPD) constitutes a major global health burden based on its high prevalence, exorbitant health-care costs, and significant mortality (Halbert et al 2006; Jemal et al 2005; Mannino et al 2007). Recent meta-analyses and large multi-national epidemiological surveys, that covered many regions world-wide and used established spirometric definitions, suggested that the prevalence of COPD has even been underestimated (Buist et al 2007; Menezes et al 2005).

Despite the lower numbers of severe (Global Initiative for Chronic Obstructive Lung Disease (GOLD) III) and very severe COPD (GOLD IV) compared to milder forms, the advanced stages of the disease are requiring the by far largest proportion of health-care resources (Chapman et al 2006) due to excessive hospitalization, exacerbation and mortality rates (Ambrosino et al 2007a). Prognosis significantly worsens in case of additional respiratory failure occurring either chronically or temporarily during an acute exacerbation. Survival is particularly reduced when ventilatory support becomes necessary (Ai-Ping et al 2005; Chu et al 2004). These patients merit special consideration not only because of poor outcome and survival rates but also in view of several therapeutical options.

If applied in defined circumstances, these options can prolong life and/or improve functional capacity, symptoms, and health-related quality of life (Rabe et al 2007). It has to be taken in account, however, that these therapies by themselves can involve considerable health-care costs. Thus, they should be used in the most efficient, evidence-based manner. Based on these considerations the present review focuses on clinically and pathophysiologically important aspects of the two major modalities for 
the treatment of acute or chronic respiratory failure in COPD: mechanical ventilation and oxygen therapy.

\section{Definitions and pathophysiology of respiratory failure}

Commonly respiratory failure results from disturbances of gas exchange due to impairments in either oxygenation, or elimination of carbon dioxide, or both (Roussos et al 2003). For clinical routine purposes, respiratory failure is usually defined by an arterial oxygen tension $\left(\mathrm{PaO}_{2}\right)$ of less than $60 \mathrm{mmHg}(<8.0 \mathrm{kpa})$ and/or an arterial carbon dioxide tension $\left(\mathrm{PaCO}_{2}\right)$ greater than $45 \mathrm{mmHg}(>6.0 \mathrm{kpa})$.

From a pathophysiological point of view the respiratory system comprises two major compartments: the lung as a gas exchange device and the ventilatory pump powering this device. Functional failure of the lung itself (type I respiratory failure) primarily results in arterial hypoxemia, associated with normal or even reduced levels of $\mathrm{PaCO}_{2}$ as a consequence of compensatory augmented ventilation. In contrast, ventilatory pump failure (type II (hypercapnic) respiratory failure) is caused by mechanical disadvantage (such as lung hyperinflation in COPD), central nervous system abnormalities, or respiratory muscle dysfunction and leads to an elevation of $\mathrm{PaCO}_{2}$ levels, often in company with hypoxemia due to alveolar hypoventilation.

In COPD, as in other conditions of respiratory illness, respiratory failure can occur as acute, chronic, or acute-on-chronic failure. In addition to ventilation/perfusion inhomogeneities, lung hyperinflation is a major factor in the pathogenesis of hypercapnic respiratory failure, being associated with a flat diaphragm and thereby diminishing muscle efficiency and increasing energy consumption (Calverley 2003). In the chronic setting, patients with COPD often show a rapid shallow breathing. This presumably represents a key protective mechanism to prevent respiratory muscle fatigue, however at the price of an insufficient alveolar ventilation (Roussos et al 2003). In severe COPD with markedly limited functional reserves, acute-on-chronic respiratory failure may aggravate the pre-existing chronic respiratory failure. This can happen when an acute deterioration of whatsoever origin, most often increased airway obstruction during acute exacerbation, poses an additional load on the respiratory system. The pre-existing mechanical disadvantage is further boosted by incomplete emptying of the lungs, leading to air trapping. This promotes a significant intrinsic positive end-expiratory airway pressure $\left(\mathrm{PEEP}_{\mathrm{i}}\right)$ which further aggravates respiratory muscle dysfunction and enhances ventilation-perfusion mismatch (Smith et al 1988).

\section{Principles of the treatment of respiratory failure}

Naturally, the prophylactic strategies against respiratory failure in COPD comprise the avoidance or reduction of disease progression and the prevention or amelioration of exacerbations by vaccination (Alfageme et al 2006; Wongsurakiat et al 2004), anti-inflammatory therapy (Burge et al 2000), long-acting bronchodilators (Mahler et al 1999; Niewoehner et al 2005), or their combination (Calverley et al 2007). In the presence of an exacerbation the treatment of airway obstruction with bronchodilators (Bach et al 2001), and the administration of systemic steroids (Niewoehner et al 1999) and antibiotics are basic in the management of acute respiratory failure. The practical aspects and therapeutic efficacies of these interventions for treating acute exacerbations have recently been reviewed in detail (MacIntyre et al 2008) and are summarized in the current COPD-update provided by GOLD (Rabe et al 2007).

Once respiratory failure is imminent, or aggravated because it has been present before, the maintenance or improvement of gas exchange by additional non-pharmacological options is strongly recommended, among them most importantly oxygen supply. This basically aims at raising the fraction of inspired and taken-up oxygen to counteract acute or chronic hypoxia and to prevent or reduce tissue hypoxia. Significant benefits for the patients are symptom relief and improved long-term survival. As a second major option, ventilatory support must be taken into consideration to raise alveolar ventilation and/or reduce mechanical load. This can be achieved either invasively or non-invasively in the intensive/intermediate care unit (ICU), emergency department, or - for long-term use - at home.

\section{Treatment of acute respiratory failure Impact of non-invasive ventilation in acute respiratory failure}

The onset of acute respiratory failure (ARF) in COPD generally marks a serious change in clinical state and is a frequent cause of admissions to emergency and/or intensive care units (ICU). Even more, ARF is also associated with excess mortality both during the hospital stay and in the months following discharge from the hospital (Connors $\mathrm{Jr}$ et al 1996; Seneff et al 1995). The long-term prognosis of patients with COPD and ARF particularly worsens if their clinical state calls for a ventilatory support, irrespective of whether this is applied invasively (Connors et al 1996) or 
non-invasively (Chu et al 2004). Despite these commonalities, the introduction of non-invasive ventilation must be considered as one of the major advances in respiratory medicine, with significant consequences in terms of improved short- and long-term outcome (Plant et al 2003).

\section{Acute hypercapnic respiratory failure following acute exacerbation}

Among the non-invasive ventilation techniques, non-invasive positive pressure ventilation (NPPV) via nasal or facial mask or a helmet (Antonelli et al 2004) is meanwhile the therapy of choice for the treatment of acute hypercapnic respiratory failure in acute exacerbations of COPD. However, also negative pressure ventilation (via an iron lung) seems to be effective in avoiding endotracheal intubation and reducing the risk of death (Corrado et al 2002). Even more, also continuous positive airway pressure (CPAP) support - though not being a ventilation in the proper sense of the word - has been proven as useful during ARF in patients with COPD (Dial et al 2006).

Randomized clinical trials as summarized in metaanalyses (Lightowler et al 2003; Peter et al 2002) and comprehensive reviews (Keenan et al 2003; Ram et al 2004) have clearly demonstrated that the supplementation of standard medical care by NPPV results in a lower mortality and risk for intubation. This is accompanied by a reduction in the number of hospital or ICU days compared to standard medical care only, which in particular might include intubation. The results make sense in view of the fact that non-invasive ventilation offers significant advantages over invasive approaches, circumventing a number of serious complications that can occur after tracheal tube insertion or tracheostomy. Complications include the possibility of ventilator-induced lung injury and the elevated risk for respiratory infections, both of which are known to be associated with invasive mechanical ventilation (Ambrosino et al 2008).

\section{Predictors of success/failure with non-invasive ventilation in acute respiratory failure}

Despite the reported effectiveness of NPPV in patients with COPD and ARF, it should be noted that the benefit from NPPV critically depends on the degree of hypercapnia and respiratory acidosis. Arterial $\mathrm{pH}$ seems to constitute the best marker reflecting both the severity of ARF and the effect of NPPV in the acute setting (Plant et al 2003). In mild exacerbations of COPD ( $\mathrm{pH}>7.35)$, NPPV seems to be of limited value and not being well tolerated by the patients, as indicated by a randomized controlled trial (Keenan et al 2005).
In accordance with these findings, in patients with very severe ARF ( $\mathrm{pH}<7.25$ ) the rate of NPPV failure was inversely related to the severity of respiratory acidosis (Ambrosino et al 2008). This indicates that severe acidosis resulting from acute exacerbation is a relevant predictor for treatment failure of NPPV (Plant et al 2001), in addition to being a prognostic factor for mortality per se (Jeffrey et al 1992; Plant et al 2000).

In this regard, the findings of recent clinical trials might seem surprising at the first view (Diaz et al 2005a; Scala et al 2007). These studies suggested that a reduced level of consciousness in acute hypercapnic respiratory failure must not necessarily be taken as a contraindication for NPPV, as had been proposed previously (Mehta et al 2001). It should be clear, however, that not only experience with the technique and the type of patient involved is required, but also a close supervision and permanent stand-by in order to initiate immediate endotracheal intubation if NPPV is not effective within short time (Scala et al 2007). Irrespective of these possibilities, the most favorable results of NPPV in ARF due to acute exacerbation have been obtained when NPPV was employed in an early stage and in patients with moderate hypercapnic respiratory failure $(\mathrm{pH}$ 7.25-7.35) (Table 1).

In addition to the severity of failure as reflected by $\mathrm{pH}$, the presence of significant comorbidities raises the probability of NPPV failure (Nava et al 2004). A large study of patients with COPD, in which a chart for NPPV failure was prospectively evaluated, revealed that in addition to low $\mathrm{pH}$ values low scores of the Glasgow Coma scale, high respiratory rates and high APACHE-II scores were related to NPPV failure (Confalonieri et al 2005). Another key indicator of failure seems to be the lack of improvement in clinical and gas exchange measures within the first hour after initiation of NPPV (Garpestad et al 2007). There are further predictors for NPPV failure that have been revealed during the last years and might be helpful for the decision on initiation and continuation of NPPV in patients with COPD and ARF (Table 1). Moreover, a number of contraindications such as persistent unconsciousness, hemodynamic instability, gastrointestinal or orofacial bleeding, a high risk for aspiration, or the inability to protect the airways have to be kept in mind when using this technique (Ambrosino et al 2007b) (Table 2).

\section{Acute hypercapnic respiratory failure following pneumonia}

Clinical studies on the use of NPPV in acute hypoxemic respiratory failure due to community-acquired pneumonia 
Table I Most important predictors for treatment success/failure in acute hypercapnic respiratory failure in COPD derived from the literature (Ambrosino et al 1995; Brochard et al 1995; Carlucci et al 2001; Carlucci et al 2003; Confalonieri et al 2005; Conti et al 2002; Meduri et al 1996; Phua et al 2005; Plant et al 2000a; Scala et al 2007; Soo Hoo et al 1994; Squadrone et al 2004), and Hill et al (2007) and Garpestad et al (2007)

\begin{tabular}{|c|c|}
\hline $\begin{array}{l}\text { Predictors for treatment } \\
\text { success }\end{array}$ & $\begin{array}{l}\text { Predictors for treatment } \\
\text { failure }\end{array}$ \\
\hline $\mathrm{pH} 7.25-7.35, \mathrm{PaCO}_{2}>45 \mathrm{mmHg}$ & $\mathrm{pH}<7.25$ \\
\hline $\mathrm{GCS}>14$ & $\mathrm{GCS} \leq \mathrm{II}$ \\
\hline APACHE-II score $<29$ & APACHE-II score > 29; \\
\hline Respiratory rate $24-30 / \mathrm{min}$ & Significant comorbidities \\
\hline Response to NPPV within $\mathrm{I}-2 \mathrm{~h}$ & Respiratory rate $>30 / \mathrm{min}$ \\
\hline $\begin{array}{l}\text { Training/experience of the team } \\
\text { with NPPV }\end{array}$ & Additional pneumonia \\
\hline \multirow[t]{6}{*}{ Standardized NPPV protocol } & Severe mask leakage \\
\hline & Patient-ventilator asynchrony \\
\hline & Ineffective triggering \\
\hline & Agitation or intolerance \\
\hline & Encephalopathy \\
\hline & Inability to clear secretions \\
\hline
\end{tabular}

(CAP) have yielded disappointing results (Ferrer et al 2003b; Honrubia et al 2005; Phua et al 2005). However, in patients with COPD and CAP at least one randomized controlled trial indicated beneficial effects of NPPV on intubation rate, the duration of stay in the ICU and short-term survival (Confalonieri et al 1999).

\section{Respiratory failure after extubation and during prolonged weaning}

According to a large randomized controlled trials, in unselected patients NPPV seems not effective in reducing re-intubation rates, if used for the treatment of overt respiratory failure occurring after extubation (Esteban et al 2004; Keenan et al 2002). An even more critical issue seems to be that in the large study of Esteban and co-workers in which at least $10 \%$ of patients had COPD, even excess mortality was observed in the NPPV group during the ICU stay (Esteban et al 2004). However, the design of this trial has been criticized on the basis of the argument that re-intubation in the NPPV group, occurring on average 10 hours later than in the control group, may have been delayed. In contrast to these findings, a previous (although non-randomized) study in patients with COPD suggested a role for NPPV in the management of post-extubation hypercapnic respiratory failure based on the fact that it significantly reduced the need for endotracheal intubation (Hilbert et al 1998).
Compared to this, a high level of evidence for the use of NPPV is available in patients with COPD and high risk for extubation failure, whereby NPPV is particularly utilized to avoid post-extubation respiratory failure and re-intubation. In this setting NPPV has been clearly shown in randomized controlled trials to reduce intubation rates and thereby improving ICU mortality, when NPPV is employed early after extubation, before the occurrence of overt respiratory failure (Ferrer et al 2006; Nava et al 2005).

Weaning from long-term invasive mechanical ventilation often turns out to be a difficult procedure in COPD; hence it is one of the major reasons for admission to specialized weaning-centers (Schonhofer et al 2002). NPPV has been proven to be useful in accelerating the weaning process when employed as a weaning strategy (Burns et al 2006). Specifically, randomized controlled design demonstrated that in patients who failed a T-piece trial, most of them having COPD, the rate of infectious complications, the duration of the ICU stay and short-term mortality were all reduced, when using additional NPPV versus standard weaning without NPPV (Ferrer et al 2003a; Nava et al 1998).

\section{Invasive mechanical ventilation in COPD}

Once the decision in favor of invasive ventilation has been made, care has to be taken that overstretching of lung parenchyma and ventilator-induced lung injury (VILI) are avoided (Tremblay et al 2006) by using low tidal volumes. One must state, however, that especially in patients with COPD

Table 2 Relative and absolute contraindications for non-invasive ventilation in the acute and chronic setting, modified from

\begin{tabular}{|c|c|}
\hline $\begin{array}{l}\text { Contraindications in acute } \\
\text { setting }\end{array}$ & $\begin{array}{l}\text { Contraindications in chronic } \\
\text { setting }\end{array}$ \\
\hline $\begin{array}{l}\text { Hemodynamic instability and } \\
\text { cardiac arrest }\end{array}$ & $\begin{array}{l}\text { Non-motivation or } \\
\text { Non-adherence to therapy }\end{array}$ \\
\hline $\begin{array}{l}\text { Impending or manifest } \\
\text { respiratory arrest }\end{array}$ & $\begin{array}{l}\text { Mask intolerance (claustrophobia, } \\
\text { facial dysmorphia) }\end{array}$ \\
\hline Severely impaired consciousness & $\begin{array}{l}\text { Excessive secretions and/or risk } \\
\text { for aspiration }\end{array}$ \\
\hline Uncontrollable agitation & $\begin{array}{l}\text { Severe comorbidities or ethical } \\
\text { concerns }\end{array}$ \\
\hline Mask intolerance & $\begin{array}{l}\text { Severe cognitive impairment } \\
\text { (dementia) }\end{array}$ \\
\hline $\begin{array}{l}\text { Significant upper gastrointestinal } \\
\text { bleeding }\end{array}$ & $\begin{array}{l}\text { Lack of any subjective or objective } \\
\text { treatment effect }\end{array}$ \\
\hline \multicolumn{2}{|l|}{ Upper airway obstruction } \\
\hline \multicolumn{2}{|l|}{ Facial trauma or surgery } \\
\hline Massive secretions/aspiration risk & \\
\hline
\end{tabular}


with severe exacerbation the impact of invasive ventilation on short- or long-term outcome has not yet been clearly shown, in contrast to patients with acute lung injury (ALI) or respiratory distress syndrome (ARDS) (ARDS Network 2000). Small tidal volumes or low inspiratory pressure levels inevitably lead to a reduction of effective minute ventilation, with the consequence that $\mathrm{PaCO}_{2}$ raises and $\mathrm{pH}$ decreases. This may be tolerated down to $\mathrm{pH}$ values of 7.10-7.20. In fact a beneficial effect of this "permissive hypercapnia" on short-term mortality has been found in different forms of acute lung injury and may also apply to COPD (Kregenow et al 2006).

Another adverse effect of invasive mechanical ventilation in COPD is the generation or aggravation of PEEP ${ }_{i}$. This is typical for those diseases which are associated with significant airway obstruction evoked by inflammation, bronchospasm or hypersecretion, with the consequence of incomplete alveolar emptying and air trapping (Pfeifer 2007). In controlled ventilation, a reduction of inspiratory time and respiratory frequency can increase expiratory time thus promoting lung deflation with the consequence of a reduction in PEEP $_{\mathrm{i}}$ (Ward et al 2008). The addition of an end-inspiratory pause is not favorable, as it impairs respiratory system mechanics and gas exchange (D'Angelo et al 1994; Georgopoulos et al 1995; Wanger et al 1996). High initial flow rates can effectively reduce the work of breathing particularly in patients with COPD undergoing pressure support ventilation (Bonmarchand et al 1996), while inadequate cycling may enhance dynamic hyperinflation during assisted ventilation.

During patient-trigged support ventilation, PEEP $_{i}$ can represent a significant load to the patient's effort to trigger the ventilator. This can result in an increased work of breathing und deleterious patient-ventilator asynchrony. In these circumstances the application of an external PEEP or its increase might be effective, as this reduces the trigger level and patient's inspiratory threshold load. Patients with an excessive drive for breathing and concomitant high respiratory frequency will enhance their PEEP $_{i}$. As a remedy, a higher level of sedation might be chosen, as far as tachypnea is not explained by other causes amenable to treatment, such as pain, fever and pulmonary embolism.

In the management of respiratory mechanics in COPD, the repeated analysis of wave forms including pressurevolume loops can be particularly helpful in order to detect relevant changes in airway resistance and $\mathrm{PEEP}_{i}$, patientventilator asynchrony, but also excessive airway secretions (Dhand 2005; Lucangelo et al 2005). An esophageal balloon allows even more sophisticated measurements, especially with regard to the work of breathing and chest wall or lung compliance (Dhand 2005).

\section{Treatment of chronic respiratory failure Mechanical ventilation in chronic hypercapnic respiratory failure}

While the occurrence of acute hypercapnic respiratory failure in the course of an acute exacerbation in COPD is clearly associated with increased mortality, the prognostic value of chronic but stable hypercapnia is much more intricate (Budweiser et al 2007c). In patients with COPD and chronic respiratory failure receiving long-term oxygen therapy (LTOT), a low level of carbon dioxide tension $\left(\mathrm{PaCO}_{2}\right)$ has even been found to be linked to elevated mortality (Chailleux et al 1996), whereas in another study similar rates of survival were observed in normocapnic $(<45 \mathrm{mmHg})$ and hypercapnic $(>45 \mathrm{mmHg})$ patients (Aida et al 1998). When $\mathrm{PaCO}_{2}$ was markedly elevated ( $>55 \mathrm{mmHg})$, long-term outcome within the first year after hospital discharge was found to be poor (Chailleux et al 1996). The same applied when hypercapnia persisted after recovery from an acute exacerbation (Costello et al 1997).

Long-term non-invasive ventilation at home aims at persistently reducing hypercapnia as one of its goals. The impact of this treatment in COPD with chronic hypercapnic respiratory failure is still controversial, particularly as far as survival is taken as outcome measure. This is indicated by a number of randomized controlled trials (Budweiser et al 2008b) which are however not devoid of methodological weaknesses (Elliott 2002; Kohnlein et al 2003). Despite these uncertainties, COPD with concomitant chronic hypercapnic respiratory failure has become one of the major indications for home mechanical ventilation (HMV), at least in Europe (Janssens et al 2003; Lloyd-Owen et al 2005). The large variability in prescription rates among different countries and institutions probably reflects the fact that the criteria for initiating home ventilation in these patients differ, similarly to the conditions and traditions of health care systems. Throughout countries, home ventilation is predominantly administered through a nasal or facial mask during the night; only a minority of patients is ventilated invasively via tracheostoma (Farre et al 2005). Recent data indicate that invasive ventilation is associated with poorer long-term outcome particularly in patients with COPD (Marchese et al 2008). 


\section{Indications for non-invasive home ventilation and selection of patients}

Following the currently accepted guidelines, a pronounced elevation of daytime $\mathrm{PaCO}_{2}$ is considered as a key indicator for the initiation of home mechanical ventilation in COPD (Rabe et al 2007). Noteworthy enough there seems to be no agreement on the required levels of hypercapnia, and these have never been verified in comparative, prospective, randomized controlled trials. As a mark for orientation, the indication for non-invasive home ventilation in COPD is often based on the statements of a Consensus Conference Report a number of years ago (Consensus Conference Report 1999). According to these, home mechanical ventilation can be justified in severe COPD after optimization of standard therapy including LTOT, if daytime $\mathrm{PaCO}_{2}$ levels during spontaneous breathing are at least $55 \mathrm{mmHg}$. The same applies if $\mathrm{PaCO}_{2}$ levels are lower $(50-54 \mathrm{mmHg})$ but at the same time significant nocturnal hypoventilation is present (Table 3).

After initiation of HMV in patients with obstructive lung diseases benefits have been reported at least with regard to the frequency of hospitalizations compared to the preceding years (Jones et al 1998; Leger et al 1994). Thus, in more mild hypercapnia $\left(\mathrm{PaCO}_{2} 50-54 \mathrm{mmHg}\right)$ a further indication for home ventilation in COPD might be that at least two episodes of acute hypercapnic respiratory failure per year occur (Consensus Conference Report 1999). Such considerations

Table 3 Indicators for the initiation of domiciliary non-invasive ventilation in COPD

Indications for domiciliary non-invasive ventilation
- According to guidelines (Consensus Conference Report 1999)
Clinical symptoms (dyspnea, morning headache, daytime sleepiness) after
optimization of standard therapy including oxygen
and
$\mathrm{PaCO}_{2} \geq 55 \mathrm{mmHg}$
or
$\mathrm{PaCO}_{2} 50-54 \mathrm{mmHg}$
and
nocturnal $\mathrm{SaO}, \mathrm{O}_{2} 88 \%$ at night for $\geq 5$ min with $\geq 2 \mathrm{~L} /$ min $\mathrm{O}_{2}$
or $\geq 2$ hospitalizations per year because of acute respiratory failure
Further individually tailored indications (derived from observational
studies):
- After prolonged mechanical ventilation (Quinnell et al 2006)
- After life-threatening exacerbation requiring ventilatory support
(Chu et al 2004)
- Patients at high risk for death, based on known risk factors (Budweiser
et al 2007b)

suggest a role for HMV beyond the reversal of chronic hypercapnia as an immediate target.

According to the current view, COPD is considered as a systemic, multidimensional disorder bearing a variety of risk factors for severe exacerbations requiring hospitalization (Garcia-Aymerich et al 2001; Kessler et al 1999) and for death from different causes (Dolan et al 2005). These risk factors favor disease instability, uncompensated respiratory failure, and as a consequence hospitalization and death. A recent comprehensive meta-analysis came to the conclusion that in severe COPD HMV is capable of evoking beneficial effects on the ventilatory pattern, thereby reducing the work of breathing and improving functional reserves (Kolodziej et al 2007). Correspondingly, the use of NPPV at home might be one important factor in counteracting episodes of impending respiratory failure, which in these multi-morbid patients easily result from exacerbations. Thus there seems to be enough reason for arguing that the eligibility for HMV should not be based on a too restrictive and simple pattern of criteria. Preferentially it should rely on a rational analysis of the individual patient's risk factor profile (Table 3). Such a view is also suggested by the results of a recent large observational study (Budweiser et al 2007b).

Moreover, a non-controlled investigation suggested that the continuation of HMV after difficult or prolonged weaning was associated with better long-term survival, compared to patients discharged without ventilatory support. Interestingly enough, this was independent from the patients' age and duration of hospital stay (Quinnell et al 2006). Thus careful administration of HMV in patients with COPD is not only likely to exert beneficial effects on the patients but also might be beneficial for the society, as it can result in a significantly lower frequency of hospital admissions and a concomitant reduction in health-care costs, as noted previously (Casanova et al 2000; Jones et al 1998; Tuggey et al 2003). Whether this will lead to reduced or balanced overall costs, still has to be checked in prospective randomized controlled trials. Recent observational data suggest that long-term management of patients with severe COPD and chronic respiratory failure by measures including HMV does not increase healthcare costs compared to LTOT treatment alone (Clini et al 2008).

\section{Effects of non-invasive home ventilation} Physiological mechanisms

It might seem surprising that the knowledge on the mechanisms underlying the effects of non-invasive HMV, especially their relative contributions under different conditions, is still rather limited. In particular the basis for the 
improvement of gas exchange during spontaneous breathing after NPPV support has not been clarified in detail (Mehta et al 2001). The hypothesis - plausible at the first sight - that non-invasive ventilation primarily allows the exhausted respiratory muscles to rest and recover probably not properly accounts for the complex mechanisms involved (Budweiser et al 2008b). This is true despite the fact that ventilatory support can be associated with a reduction in the activation of respiratory muscles under certain circumstances, as shown in earlier studies (Carrey et al 1990; Nava et al 1993; Renston et al 1994).

However, restoration of chemosensitivity (Mehta et al 2001) and changes in ventilatory pattern including an increase in tidal and minute volumes, as well as the concomitant reduction of respiratory frequency, may play a more prominent role in long-term NPPV. The relevance of these factors has been demonstrated in sophisticated physiological studies (Ambrosino et al 1992; Diaz et al 2002; Diaz et al 2005 b). Even more important seems to be that the amelioration of the ventilatory pattern is preserved during spontaneous breathing (Ambrosino et al 1992; Diaz et al 2002; Diaz et al 2005b). This could well underlie the sustained reduction of $\mathrm{PaCO}_{2}$, which again induces positive effects on lung hyperinflation and respiratory muscles (Budweiser et al 2005; Diaz et al 2002).

\section{Subjective effects}

The beneficial effects of NPPV on breathing pattern, respiratory muscles and respiratory mechanics and the subsequent improvement in functional reserves (Kolodziej et al 2007) are reflected in a reduction of dyspnea. Considering dyspnea as an integrative measure of efficacy, this seems remarkable. It is a very consistent effect of long-term NPPV demonstrated by randomized controlled clinical trials (Casanova et al 2000; Clini et al 2002; Diaz et al 2005b). These findings also fit well into the picture provided by the data on health-related quality of life (HRQL).

The majority of controlled (Clini et al 2002; Meecham Jones et al 1995) and non-controlled trials (Perrin et al 1997; Sivasothy et al 1998; Windisch 2008) dealing with HRQL revealed positive effects of the long-term use of NPPV, irrespective of the fact whether generic measures were employed or disease-specific questionnaires designed for patients with chronic respiratory failure, such as the Maugeri Foundation Respiratory Failure Questionnaire (MRF-28) or the Severe Respiratory Insufficiency (SRI) questionnaire. The latter has recently been validated especially with regard to COPD and HMV (Windisch et al 2008). This again seems an important result, since HRQL is an important marker in chronic hypercapnic respiratory failure and even might carry predictive information on long-term survival, though this seems to depend on the type of disease (Budweiser et al 2007a).

\section{Effects on exercise capacity}

The patients' global functional capacity appears to be well reflected in the 6-minute walking distance (6-MWD) as a clinically useful and easy-to-assess measure (Carter et al 2003). It also represents a prognostic marker in COPD (Pinto-Plata et al 2004), particularly in patients with chronic hypercapic respiratory failure (Budweiser et al 2008a). In the majority of studies there were no direct effects of longterm NPPV on 6-MWD (Clini et al 2002; Meecham Jones et al 1995; Schonhofer et al 2007; Strumpf et al 1991), and 6-MWD was found to be improved in only two randomized controlled trials which, however, covered only a short followup time (Diaz et al 2005b; Renston et al 1994).

Obviously, while having positive effects at rest, intermittent nocturnal HMV is not sufficient to compensate for the worsening of dynamic hyperinflation during exercise, which is considered as a major limiting factor of exercise capacity in severe COPD (O’Donnell et al 2001). This, however, does not exclude that NPPV applied during walking exerts positive effects on oxygenation, dyspnea and walking distance. Indeed such effects have been recently demonstrated in a randomized cross-over trial in a small sample of patients (Dreher et al 2007).

\section{Effects on long-term survival}

With regard to long-term prognosis the role of non-invasive ventilation in COPD and chronic hypercapnic failure is still under discussion. Two randomized controlled trials involving follow-up periods of 1 and 2 years, respectively, did not indicate domiciliary intermittent non-invasive ventilation to be effective in improving long-term survival compared to LTOT alone (Casanova et al 2000; Clini et al 2002). However, these trials comprised relatively small samples of patients and raised a number of objections regarding patients' selection, ineffective ventilation or pressure levels, and poor adherence to therapy.

Thus non-randomized trials including a broad range of patients still seem to have a potential if analyzed and interpreted with caution. In a recent large observational study comprising an observation period of up to 4 years, we found that patients with COPD and non-invasive HMV showed a much better long-term survival than a control group of patients who could not be successfully adapted to HMV due 
to a variety of reasons (Budweiser et al 2007b). Of course, in view of the non-randomized design, these data have weaknesses, though the difference between treatment and control group at baseline was rather small. Still the results need to be checked by large randomized controlled trials, one such trial being currently underway (Kohnlein et al 2004).

\section{Technical aspects of non-invasive home ventilation}

One of the most important factors for a success of NPPV, especially a marked reduction in $\mathrm{PaCO}_{2}$, appears to be the achievement of effective ventilation by applying sufficient levels of inspiratory pressure. In accordance with this, studies capable of demonstrating beneficial effects of NPPV on gas exchange, lung function, sleep, or health-related quality of life (Budweiser et al 2005; Budweiser et al 2007c; Meecham Jones et al 1995; Windisch et al 2005) all used high inspiratory pressures, up to $28 \mathrm{~cm} \mathrm{H}_{2} \mathrm{O}$, which were still well tolerated by the patients. In contrast, the application of lower inspiratory pressure levels $\left(10-15 \mathrm{~cm} \mathrm{H}_{2} \mathrm{O}\right)$, as chosen in the two available randomized controlled trials (Casanova et al 2000; Clini et al 2002), was associated with an unfavorable outcome. Though these parallels are not compelling, they are at least suggestive.

During support-ventilation modes, in addition to high pressure levels, a positive end-expiratory pressure (3-5 cm $\mathrm{H}_{2} \mathrm{O}$ ) and low trigger levels have been found to effectively counteract PEEP $_{\mathrm{i}}$ (Nava et al 1993), minimizing the work of breathing and optimizing patient-ventilator synchrony. To allow for maximal expiratory emptying of the lung, inspiratory time should be chosen as short as possible when using controlled ventilation modes, with a target ratio of inspiration to expiration time (I:E) of at least $1: 2$ to $1: 3$.

Taking well-chosen ventilator settings and the usage of modern, sophisticated ventilators for granted, the potential of non-invasive ventilation can be fully utilized only if patients are motivated, well instructed and encouraged. This is of special importance in the initial phase of adaptation to the therapy. For achieving this, the availability of an experienced team as well as sufficient time for familiarization within an in-patient setting appears of utmost value. Today the high rates of inacceptance as reported in the early years of HMV (Lin 1996; Strumpf et al 1991) would not be considered acceptable and justified by objective reasons. Of course, contraindications have still to be taken into account (Table 2).

A further important issue is the regular follow-up of the patients. This serves for assessing the effectiveness of ventilation and adherence to therapy as well as for resolving potential adverse effects (Hill 2004). In case that an early withdrawal of NPPV turns out to be necessary, it should be noted that a benefit from this therapy has been reported even for such short-term use (Diaz et al 2002; Diaz et al 2005b). Obviously NPPV can be efficient even if bolstering functional reserves only within a short episode of most severe, acute deterioration (Budweiser et al 2008b).

\section{Oxygen therapy}

\section{Physiological consequences of hypoxemia}

Once acute hypoxemia reaches a critical limit, various physiological consequences take place. These include an increase in minute ventilation, compensatory tachycardia to increase cardiac output, dilation of peripheral vessels, and constriction of pulmonary vasculature, with the result of a reduction of ventilation/perfusion mismatching. In the long run, these events plus the stimulation of erythropoietin production causing polycythemia lead to functional and structural changes including cor pulmonale and pulmonary hypertension (Kim et al 2008). Beyond its effects on the cardiopulmonary system, hypoxemia causes a number of other consequences, which include the reduction of specific neurocognitive functions as well as non-specific symptoms such as headache, thoracic oppression and agitations.

\section{Oxygen for acute hypoxemic respiratory failure}

Based on the physiological responses to hypoxemia, the administration of oxygen during acute respiratory failure as indicated by acute hypoxia and dyspnea can be considered as a matter of course. Accordingly, in current guidelines (Rabe et al 2007) for the management of acute exacerbations in COPD it is recommended that "the first actions when a patient reaches the emergency department are to provide supplemental oxygen therapy and to determine whether the exacerbation is life threatening". Although this intervention is well established in clinical practice and oxygen supply is considered as biologically justified, the evidence on oxygen supply in acute respiratory failure from randomized controlled trials is surprisingly limited (Schumaker et al 2004).

It must however be admitted that appropriate clinical trials are difficult to perform in such clinically unstable conditions (Plant et al 2003) and moreover encounter ethical concerns. Short-term clinical trials in patients with COPD and stable hypoxemia and current pathophysiological concepts of dyspnea (O'Donnell et al 2007) suggest that oxygen is effective both in improving oxygen saturation and in reducing breathlessness in the acute setting. The alleviation of symptoms is presumably related to the decreases in minute ventilation and/or respiratory rate, which reduce the work 
of breathing and the risk for respiratory decompensation (Aubier et al 1980a).

To achieve these effects and sufficient levels of oxygenation, $\left(\mathrm{PaO}_{2}>60 \mathrm{mmHg}\right.$ or oxygen saturation $\left.\left(\mathrm{SaO}_{2}\right)>90 \%\right)$ (Rabe et al 2007), nasal prongs or high flow devices (Venturi masks) may be used, the latter being more reliable for delivering a defined oxygen amount in the acute setting (Bazuaye et al 1992). It is currently unknown whether the delivery of oxygen in the presence of $\mathrm{PaO}_{2}$ values $>60 \mathrm{mmHg}$ is beneficial in acute exacerbations. In any case, short-term and repeated evaluations of gas exchange indices are commonly recommended to verify treatment effects and to exclude a significant $\mathrm{CO}_{2}$ retention or an impending respiratory acidosis that may result from the reduction in hypoxic drive to breathe, or ventilation/perfusion mismatching (Aubier et al 1980b; Robinson et al 2000). As yet, clinical investigations dealing with these safety issues in, however, small samples of patients have suggested that the risk of worsening an existing hypercapnia is low during controlled oxygen delivery in acute exacerbations (Agusti et al 1999; Gomersall et al 2002). It may predominantly occur in patients with very severe initial hypercapnia (Moloney et al 2001).

The idea has been proposed that inhalation of nitric oxide in addition to oxygen might have benefits compared to oxygen alone in patients with COPD. There is, however, no substantial evidence on clinically relevant add-on effects, as indicated by studies that found unchanged, or even impaired, oxygenation in patients of different severity (Kanniess et al 2001; Melsom et al 2007). As a consequence, this combined therapy is not recommended in COPD (Germann et al 2005). More promising seems the addition of a helium-oxygen mixture based on the fluid-mechanical and physiological properties of helium. This has the potential to provide benefits regarding a reduction of airway resistance and work of breathing, which might result in lower intubation rates compared to standard inhalation gas (Schumaker et al 2004). However, these findings have to be substantiated in future randomized controlled trials.

\section{Long-term oxygen therapy for chronic hypoxemic respiratory failure}

LTOT is widely accepted as treatment to counterbalance chronic, significant hypoxemia in COPD although it is known to represent a considerable amount of still increasing health-care costs (Croxton et al 2006). Despite this, it has been argued that the critical $\mathrm{PaO}_{2}$ levels allowing the prescribing of LTOT according to accepted guidelines (Rabe et al 2007) (Table 4) are probably not fully adequate. They do not properly take into account other important factors of the disease such as a low BMI, comorbidities, or frequent exacerbations, all of which may favor a benefit from LTOT (O’Reilly et al 2007).

\section{Effects of LTOT on survival}

Among the treatment modalities for COPD, LTOT is considered since many years as one of those interventions for which a clear-cut survival benefit is given. Indeed, more than 25 years ago two randomized controlled trials were capable of demonstrating a survival benefit from LTOT in patients with severe COPD and persistent hypoxemia at rest (MRC 1981; NOTT 1980). The patients included in these long-term trials either showed an arterial $\mathrm{PaO}_{2}$ level $\leq 55 \mathrm{mmHg}$ or of $\leq 59 \mathrm{mmHg}$ in case of additional peripheral edema, polycythemia or signs for cor pulmonale (NOTT 1980), or they showed $\mathrm{PaO}_{2}$ levels ranging from 40 to $60 \mathrm{mmHg}$ and coexisting hypercapnia or congestive heart failure (MRC 1981). These two clinical trials represent major advances in respiratory medicine and are most often used as scientific basis for the prescription of LTOT.

Despite this one should not ignore their limitations, among them the relatively small numbers of patients $(n=87$ and $n=203$, respectively) compared to present-day standards and changes in overall treatment regimes in the meantime (Kim et al 2008). Nevertheless, there was an impressive benefit regarding long-term survival in patients receiving LTOT, which was closely related to the amount of daily use. The effect on long-term prognosis was particularly pronounced in patients using oxygen on average $\geq 15$ or $\geq 16$ hours/day, respectively. Viewed from the other side, such treatments effects have highlighted the major role of chronic hypoxemia as a predictor of long-term survival in COPD (Dolan et al 2005), and long-term follow-up investigations have essentially confirmed this relationship (Aida et al 1998; Chailleux et al 1996; Dubois et al 1994).

In contrast to the more severely affected patients, those with more mild daytime resting hypoxemia, ie, $\mathrm{PaO}_{2}$

Table 4 Major indications for long-term oxygen therapy (LTOT) summarized from GOLD guidelines (Rabe et al 2007) and national standards (BTS 1997; Magnussen et al 200I; NICE 2004)

Indications for Long-term oxygen therapy
$\mathrm{PaO}_{2} \leq 55 \mathrm{mmHg}$ or $\mathrm{SaO}_{2} \leq 88 \%$ at rest during daytime spontaneous
breathing
$\mathrm{PaO}_{2}>55$ but $\leq 60 \mathrm{mmHg}$ in the presence of polycythemia, evidence or
signs for cor pulmonale or pulmonary hypertension
During special conditions in patients without daytime hypoxemia but
$\mathrm{PaO}_{2}<55 \mathrm{mmHg}$ during sleep or exercise (when CPAP is not indicated)


levels $>55 \mathrm{mmHg}$ (Gorecka et al 1997) or $>60 \mathrm{mmHg}$ (Fletcher et al 1992), did not show significant responses to LTOT in terms of survival within randomized controlled trials. The same was found for patients without marked daytime hypoxemia but nocturnal desaturations (Chaouat et al 1999; Fletcher et al 1992). A potential limitation of these studies, however, is that the daily average time of oxygen use may have been too short to induce recognizable survival benefits in less ill patients.

\section{Effects of oxygen on other outcomes}

Supplemental oxygen has been shown to reduce the sensation of dyspnea and to improve exercise capacity in patients with resting daytime hypoxemia (Lane et al 1987; Swinburn et al 1991). Such beneficial short-term effects during exercise can also been achieved in milder forms of hypoxemia, which do not reach the critical limit for the definition of hypoxic respiratory failure $\left(\mathrm{PaO}_{2}>60 \mathrm{mmHg}\right)$ at rest (Dean et al 1992; Fujimoto et al 2002). Presumably the underlying mechanisms involve a decrease in minute ventilation and concomitantly dynamic hyperinflation. These are accompanied by improvements in pulmonary hemodynamics and oxygen delivery which improve respiratory muscle function (Kim et al 2008).

Additionally there is evidence that in patients with chronic hypoxemia LTOT can induce subjective benefits regarding the presence of neurophysiological symptoms, anxiety, depression and health-related quality of life (HRQL) (Eaton et al 2004; Heaton et al 1983). In patients showing only transient hypoxemia during exercise, the randomized controlled trials have provided only mixed evidence regarding effects of LTOT on HRQL (Eaton et al 2002; McDonald et al 1995; Nonoyama et al 2007). Similarly, the rationale for administering supplemental oxygen during sleep in patients showing only nocturnal desaturations has not yet been clearly supported by data. Accordingly, a recent comprehensive prospective study indicated that nocturnal desaturations are not linked to impairments of HRQL, sleep quality and daytime vigilance (Lewis et al 2008).

In addition to the favorable results of LTOT on survival, beneficial effects on pulmonary hemodynamics have been described (NOTT 1980), which was essentially confirmed by later investigations (Zielinski et al 1998). This association probably represents an indirect, not a direct, causal relationship. Irrespective of this it may significantly contribute to the positive effects of LTOT on mortality and hospitalization rate (Ringbaek et al 2002), as pulmonary hypertension and cor pulmonale are known to be major factors in the long-term outcome of patients with COPD (Kessler et al 1999; Oswald-Mammosser et al 1995). Taken together, these results indicate that in patients without daytime hypoxemia but $\mathrm{PaO}_{2}<55 \mathrm{mmHg}$ during sleep or exercise, LTOT has to be considered. This particularly applies in the case that the optimization of other treatments such as CPAP that might also be sometimes indicated does not suffice to reverse hypoxemia (Table 4).

In summary, the following statements can be made on the basis of the data described.

- In severe acute exacerbations of COPD with acute respiratory failure, controlled oxygen delivery is a reasonable and effective approach to relieve symptoms, counteract hypoxemia and reduce the work of breathing.

- In COPD with acute hypercapnic respiratory failure, noninvasive ventilation is highly recommended, particularly in patients with mild to moderate respiratory acidosis. Non-invasive ventilation has the potential to reduce the risk for invasive ventilation and the associated complications, as well as to improve overall ICU and in-hospital outcome.

- In COPD with clinically relevant chronic hypoxemia, LTOT is strongly indicated to improve hemodynamic parameters, long-term prognosis and HRQL.

- In COPD with chronic hypercapnic respiratory failure, the role of long-term non-invasive home ventilation for survival has not yet been unambiguously demonstrated. However, a number of investigations point towards significant benefits in subjective and physiological outcomes.

- Taken together, respiratory failure in COPD must be considered as a serious or even life-threatening complication. Controlled oxygen supply and non-invasive mechanical ventilation are two effective components of an evidence-based, comprehensive management of respiratory failure. Their rational use has the potential to significantly ameliorate the patients' symptoms and to improve survival.

\section{Disclosures}

The authors have no conflicts of interest to disclose.

\section{References}

Agusti AG, Carrera M, Barbe F, et al. 1999. Oxygen therapy during exacerbations of chronic obstructive pulmonary disease. Eur Respir J, 14:934-9.

Ai-Ping C, Lee KH, Lim TK, 2005. In-hospital and 5-year mortality of patients treated in the ICU for acute exacerbation of COPD: a retrospective study. Chest, 128:518-24. 
Aida A, Miyamoto K, Nishimura M, et al. 1998. Prognostic value of hypercapnia in patients with chronic respiratory failure during long-term oxygen therapy. Am J Respir Crit Care Med, 158:188-93.

Alfageme I, Vazquez R, Reyes N, et al. 2006. Clinical efficacy of antipneumococcal vaccination in patients with COPD. Thorax, 61:189-95.

Ambrosino N, Nava S, Bertone P, et al. 1992. Physiologic evaluation of pressure support ventilation by nasal mask in patients with stable COPD. Chest, 101:385-91.

Ambrosino N, Simonds A. 2007a. The clinical management in extremely severe COPD. Respir Med, 101:1613-24.

Ambrosino N, Vagheggini G 2007b. Non-invasive ventilation in exacerbations of COPD. Int J Chron Obstruct Pulmon Dis, 2:471-6.

Ambrosino N, Vagheggini G. 2008. Noninvasive positive pressure ventilation in the acute care setting: where are we? Eur Respir $J$, 31:874-86.

Antonelli M, Pennisi MA, Pelosi P, et al. 2004. Noninvasive positive pressure ventilation using a helmet in patients with acute exacerbation of chronic obstructive pulmonary disease: a feasibility study. Anesthesiology, 100:16-24.

ARDS Network. 2000. Ventilation with lower tidal volumes as compared with traditional tidal volumes for acute lung injury and the acute respiratory distress syndrome. The Acute Respiratory Distress Syndrome Network. N Engl J Med, 342:1301-8.

Aubier M, Murciano D, Fournier M, et al. 1980a. Central respiratory drive in acute respiratory failure of patients with chronic obstructive pulmonary disease. Am Rev Respir Dis, 122:191-9.

Aubier M, Murciano D, Milic-Emili J, et al. 1980b. Effects of the administration of $\mathrm{O} 2$ on ventilation and blood gases in patients with chronic obstructive pulmonary disease during acute respiratory failure. Am Rev Respir Dis, 122:747-54.

Bach PB, Brown C, Gelfand SE, et al. 2001. Management of acute exacerbations of chronic obstructive pulmonary disease: a summary and appraisal of published evidence. Ann Intern Med, 134:600-20.

Bazuaye EA, Stone TN, Corris PA, et al. 1992. Variability of inspired oxygen concentration with nasal cannulas. Thorax, 47:609-11.

Bonmarchand G, Chevron V, Chopin C, et al. 1996. Increased initial flow rate reduces inspiratory work of breathing during pressure support ventilation in patients with exacerbation of chronic obstructive pulmonary disease. Intensive Care Med, 22:1147-54.

Budweiser S, Heidtkamp F, Jorres RA, et al. 2008a. Predictive significance of the six-minute walk distance for long-term survival in chronic hypercapnic respiratory failure. Respiration, 75:418-26.

Budweiser S, Heinemann F, Fischer W, et al. 2005. Long-term reduction of hyperinflation in stable COPD by non-invasive nocturnal home ventilation. Respir Med, 99:976-84.

Budweiser S, Hitzl AP, Joerres RA, et al. 2007a. Health-related quality of life and long-term prognosis in chronic hypercapnic respiratory failure: a prospective survival analysis. Respir Res, 8:92.

Budweiser S, Hitzl AP, Jorres RA, et al. 2007b. Impact of non-invasive home ventilation on long-term survival in chronic hypercapnic COPD - a prospective observational study. Int J Clin Pract, 61:1516-22.

Budweiser S, Jorres RA, Pfeifer M. 2008b. Noninvasive home ventilation for chronic obstructive pulmonary disease: indications, utility and outcome. Curr Opin Pulm Med, 14:128-34.

Budweiser S, Jorres RA, Riedl T, et al. 2007c. Predictors of survival in COPD patients with chronic hypercapnic respiratory failure receiving noninvasive home ventilation. Chest, 131:1650-8.

Buist AS, McBurnie MA, Vollmer WM, et al. 2007. International variation in the prevalence of COPD (the BOLD Study): a population-based prevalence study. Lancet, 370:741-50.

Burge PS, Calverley PM, Jones PW, et al. 2000. Randomised, double blind, placebo controlled study of fluticasone propionate in patients with moderate to severe chronic obstructive pulmonary disease: the ISOLDE trial. BMJ, 320:1297-303.

Burns KE, Adhikari NK, Meade MO. 2006. A meta-analysis of noninvasive weaning to facilitate liberation from mechanical ventilation. Can $J$ Anaesth, 53:305-15.
Calverley PM. 2003. Respiratory failure in chronic obstructive pulmonary disease. Eur Respir J Suppl, 47:26s-30s.

Calverley PM, Anderson JA, Celli B, et al. 2007. Salmeterol and fluticasone propionate and survival in chronic obstructive pulmonary disease. N Engl J Med, 356:775-89.

Carrey Z, Gottfried SB, Levy RD. 1990. Ventilatory muscle support in respiratory failure with nasal positive pressure ventilation. Chest, 97:150-8.

Carter R, Holiday DB, Nwasuruba C, et al. 2003. 6-minute walk work for assessment of functional capacity in patients with COPD. Chest, 123:1408-15.

Casanova C, Celli BR, Tost L, et al. 2000. Long-term controlled trial of nocturnal nasal positive pressure ventilation in patients with severe COPD. Chest, 118:1582-90.

Chailleux E, Fauroux B, Binet F, et al. 1996. Predictors of survival in patients receiving domiciliary oxygen therapy or mechanical ventilation. A 10-year analysis of ANTADIR Observatory. Chest, 109:741-9.

Chaouat A, Weitzenblum E, Kessler R, et al. 1999. A randomized trial of nocturnal oxygen therapy in chronic obstructive pulmonary disease patients. Eur Respir J, 14:1002-8.

Chapman KR, Mannino DM, Soriano JB, et al. 2006. Epidemiology and costs of chronic obstructive pulmonary disease. Eur Respir J, $27: 188-207$

Chu CM, Chan VL, Lin AW, et al. 2004. Readmission rates and life threatening events in COPD survivors treated with non-invasive ventilation for acute hypercapnic respiratory failure. Thorax, 59:1020-5.

Clini E, Sturani C, Rossi A, et al. 2002. The Italian multicentre study on noninvasive ventilation in chronic obstructive pulmonary disease patients. Eur Respir J, 20:529-38.

Clini EM, Magni G, Crisafulli E, et al. 2008. Home Non-Invasive Mechanical Ventilation and Long-Term Oxygen Therapy in Stable Hypercapnic Chronic Obstructive Pulmonary Disease Patients: Comparison of Costs. Respiration.

Confalonieri M, Garuti G, Cattaruzza MS, et al. 2005. A chart of failure risk for noninvasive ventilation in patients with COPD exacerbation. Eur Respir J, 25:348-55.

Confalonieri M, Potena A, Carbone G, et al. 1999. Acute respiratory failure in patients with severe community-acquired pneumonia. A prospective randomized evaluation of noninvasive ventilation. Am J Respir Crit Care Med, 160:1585-91.

Connors AF Jr., Dawson NV, Thomas C, et al. 1996. Outcomes following acute exacerbation of severe chronic obstructive lung disease. The SUPPORT investigators (Study to Understand Prognoses and Preferences for Outcomes and Risks of Treatments). Am J Respir Crit Care Med, 154:959-67.

Consensus Conference Report 1999. Clinical indications for noninvasive positive pressure ventilation in chronic respiratory failure due to restrictive lung disease, COPD, and nocturnal hypoventilation - a consensus conference report. Chest, 116:521-34.

Corrado A, Confalonieri M, Marchese S, et al. 2002. Iron lung vs mask ventilation in the treatment of acute on chronic respiratory failure in COPD patients: a multicenter study. Chest, 121:189-95.

Costello R, Deegan P, Fitzpatrick M, et al. 1997. Reversible hypercapnia in chronic obstructive pulmonary disease: a distinct pattern of respiratory failure with a favorable prognosis. Am J Med, 102:239-44.

Croxton TL, Bailey WC. 2006. Long-term oxygen treatment in chronic obstructive pulmonary disease: recommendations for future research: an NHLBI workshop report. Am J Respir Crit Care Med, 174:373-8.

D’Angelo E, Prandi E, Marazzini L, et al. 1994. Dependence of maximal flow-volume curves on time course of preceding inspiration in patients with chronic obstruction pulmonary disease. Am J Respir Crit Care Med, 150:1581-6.

Dean NC, Brown JK, Himelman RB, et al. 1992. Oxygen may improve dyspnea and endurance in patients with chronic obstructive pulmonary disease and only mild hypoxemia. Am Rev Respir Dis, 146:941-5.

Dhand R. 2005. Ventilator graphics and respiratory mechanics in the patient with obstructive lung disease. Respir Care, 50:246-61. 
Dial S, Menzies D. 2006. Is there a role for mask continuous positive airway pressure in acute respiratory failure due to COPD? Lessons from a retrospective audit of 3 different cohorts. Int J Chron Obstruct Pulmon Dis, 1:65-72.

Diaz GG, Alcaraz AC, Talavera JC, et al. 2005a. Noninvasive positivepressure ventilation to treat hypercapnic coma secondary to respiratory failure. Chest, 127:952-60.

Diaz O, Begin P, Andresen M, et al. 2005b. Physiological and clinical effects of diurnal noninvasive ventilation in hypercapnic COPD. Eur Respir J, 26:1016-23.

Diaz O, Begin P, Torrealba B, et al. 2002. Effects of noninvasive ventilation on lung hyperinflation in stable hypercapnic COPD. Eur Respir $J$, 20:1490-8.

Dolan S, Varkey B. 2005. Prognostic factors in chronic obstructive pulmonary disease. Curr Opin Pulm Med, 11:149-52.

Dreher M, Storre JH, Windisch W. 2007. Noninvasive ventilation during walking in patients with severe COPD: a randomised cross-over trial. Eur Respir J, 29:930-6.

Dubois P, Jamart J, Machiels J, et al. 1994. Prognosis of severely hypoxemic patients receiving long-term oxygen therapy. Chest, 105:469-74.

Eaton T, Garrett JE, Young P, et al. 2002. Ambulatory oxygen improves quality of life of COPD patients: a randomised controlled study. Eur Respir J, 20:306-12.

Eaton T, Lewis C, Young P, et al. 2004. Long-term oxygen therapy improves health-related quality of life. Respir Med, 98:285-93.

Elliott MW. 2002. Noninvasive ventilation in chronic ventilatory failure due to chronic obstructive pulmonary disease. Eur Respir J, 20:511-4.

Esteban A, Frutos-Vivar F, Ferguson ND, et al. 2004. Noninvasive positivepressure ventilation for respiratory failure after extubation. $N$ Engl $J$ Med, 350:2452-60.

Farre R, Lloyd-Owen SJ, Ambrosino N, et al. 2005. Quality control of equipment in home mechanical ventilation: a European survey. Eur Respir J, 26:86-94.

Ferrer M, Esquinas A, Arancibia F, et al. 2003a. Noninvasive ventilation during persistent weaning failure: a randomized controlled trial. Am J Respir Crit Care Med, 168:70-6.

Ferrer M, Esquinas A, Leon M, et al. 2003b. Noninvasive ventilation in severe hypoxemic respiratory failure: a randomized clinical trial. Am J Respir Crit Care Med, 168:1438-44.

Ferrer M, Valencia M, Nicolas JM, et al. 2006. Early noninvasive ventilation averts extubation failure in patients at risk: a randomized trial. Am J Respir Crit Care Med, 173:164-70.

Fletcher EC, Donner CF, Midgren B, et al. 1992. Survival in COPD patients with a daytime $\mathrm{PaO}_{2}$ greater than $60 \mathrm{~mm} \mathrm{Hg}$ with and without nocturnal oxyhemoglobin desaturation. Chest, 101:649-55.

Fujimoto K, Matsuzawa Y, Yamaguchi S, et al. 2002. Benefits of oxygen on exercise performance and pulmonary hemodynamics in patients with COPD with mild hypoxemia. Chest, 122:457-63.

Garcia-Aymerich J, Monso E, Marrades RM, et al. 2001. Risk factors for hospitalization for a chronic obstructive pulmonary disease exacerbation. EFRAM study. Am J Respir Crit Care Med, 164:1002-7.

Garpestad E, Brennan J, Hill NS. 2007. Noninvasive ventilation for critical care. Chest, 132:711-20.

Georgopoulos D, Mitrouska I, Markopoulou K, et al. 1995. Effects of breathing patterns on mechanically ventilated patients with chronic obstructive pulmonary disease and dynamic hyperinflation. Intensive Care Med, 21:880-6.

Germann P, Braschi A, Della RG, et al. 2005. Inhaled nitric oxide therapy in adults: European expert recommendations. Intensive Care Med, $31: 1029-41$

Gomersall CD, Joynt GM, Freebairn RC, et al. 2002. Oxygen therapy for hypercapnic patients with chronic obstructive pulmonary disease and acute respiratory failure: a randomized, controlled pilot study. Crit Care Med, 30:113-6.

Gorecka D, Gorzelak K, Sliwinski P, et al. 1997. Effect of long-term oxygen therapy on survival in patients with chronic obstructive pulmonary disease with moderate hypoxaemia. Thorax, 52:674-9.
Halbert RJ, Natoli JL, Gano A, et al. 2006. Global burden of COPD: systematic review and meta-analysis. Eur Respir J, 28:523-32.

Heaton RK, Grant I, McSweeny AJ, et al. 1983. Psychologic effects of continuous and nocturnal oxygen therapy in hypoxemic chronic obstructive pulmonary disease. Arch Intern Med, 143:1941-7.

Hilbert G, Gruson D, Portel L, et al. 1998. Noninvasive pressure support ventilation in COPD patients with postextubation hypercapnic respiratory insufficiency. Eur Respir J, 11:1349-53.

Hill NS. 2004. Noninvasive ventilation for chronic obstructive pulmonary disease. Respir Care, 49:72-87.

Honrubia T, Garcia Lopez FJ, Franco N, et al. 2005. Noninvasive vs conventional mechanical ventilation in acute respiratory failure: a multicenter, randomized controlled trial. Chest, 128:3916-24.

Janssens JP, Derivaz S, Breitenstein E, et al. 2003. Changing patterns in long-term noninvasive ventilation: a 7-year prospective study in the Geneva Lake area. Chest, 123:67-79.

Jeffrey AA, Warren PM, Flenley DC. 1992. Acute hypercapnic respiratory failure in patients with chronic obstructive lung disease: risk factors and use of guidelines for management. Thorax, 47:34-40.

Jemal A, Ward E, Hao Y, et al. 2005. Trends in the leading causes of death in the United States, 1970-2002. JAMA, 294:1255-9.

Jones SE, Packham S, Hebden M, et al. 1998. Domiciliary nocturnal intermittent positive pressure ventilation in patients with respiratory failure due to severe COPD: long-term follow up and effect on survival. Thorax, 53:495-8.

Kanniess F, Jorres RA, Magnussen H. 2001. Combined inhalation of nitric oxide and oxygen in patients with moderate to severe COPD: effect on blood gases. Respir Med, 95:927-34.

Keenan SP, Powers C, McCormack DG, et al. 2002. Noninvasive positivepressure ventilation for postextubation respiratory distress: a randomized controlled trial. JAMA, 287:3238-44.

Keenan SP, Powers CE, McCormack DG. 2005. Noninvasive positivepressure ventilation in patients with milder chronic obstructive pulmonary disease exacerbations: a randomized controlled trial. Respir Care, 50:610-6.

Keenan SP, Sinuff T, Cook DJ, et al. 2003. Which patients with acute exacerbation of chronic obstructive pulmonary disease benefit from noninvasive positive-pressure ventilation? A systematic review of the literature. Ann Intern Med, 138:861-70.

Kessler R, Faller M, Fourgaut G, et al. 1999. Predictive factors of hospitalization for acute exacerbation in a series of 64 patients with chronic obstructive pulmonary disease. Am J Respir Crit Care Med, 159:158-64

Kim V, Benditt JO, Wise RA, et al. 2008. Oxygen therapy in chronic obstructive pulmonary disease. Proc Am Thorac Soc, 5:513-8.

Kohnlein T, Criee CP, Kohler D, et al. 2004. [Multicenter study on "noninvasive ventilation in patients with severe chronic obstructive pulmonary disease and emphysema(COPD)"'. Pneumologie, 58:566-9.

Kohnlein T, Welte T. 2003. Noninvasive ventilation in stable chronic obstructive pulmonary disease. Eur Respir J, 21:558-9.

Kolodziej MA, Jensen L, Rowe B, et al. 2007. Systematic review of noninvasive positive pressure ventilation in severe stable COPD. Eur Respir J, 30:293-306.

Kregenow DA, Rubenfeld GD, Hudson LD, et al. 2006. Hypercapnic acidosis and mortality in acute lung injury. Crit Care Med, 34:1-7.

Lane R, Cockcroft A, Adams L, et al. 1987. Arterial oxygen saturation and breathlessness in patients with chronic obstructive airways disease. Clin Sci (Lond), 72:693-8.

Leger P, Bedicam JM, Cornette A, et al. 1994. Nasal intermittent positive pressure ventilation. Long-term follow-up in patients with severe chronic respiratory insufficiency. Chest, 105:100-5.

Lewis CA, Ferguson W, Eaton T, et al. 2008. Isolated nocturnal desaturation in COPD: prevalence and impact on quality of life and sleep. Thorax,

Lightowler JV, Wedzicha JA, Elliott MW, et al. 2003. Non-invasive positive pressure ventilation to treat respiratory failure resulting from exacerbations of chronic obstructive pulmonary disease: Cochrane systematic review and meta-analysis. $B M J, 326: 185$. 
Lin CC. 1996. Comparison between nocturnal nasal positive pressure ventilation combined with oxygen therapy and oxygen monotherapy in patients with severe COPD. Am J Respir Crit Care Med, 154:353-8.

Lloyd-Owen SJ, Donaldson GC, Ambrosino N, et al. 2005. Patterns of home mechanical ventilation use in Europe: results from the Eurovent survey. Eur Respir J, 25:1025-31.

Lucangelo U, Bernabe F, Blanch L. 2005. Respiratory mechanics derived from signals in the ventilator circuit. Respir Care, 50:55-65.

MacIntyre N, Huang YC. 2008. Acute exacerbations and respiratory failure in chronic obstructive pulmonary disease. Proc Am Thorac Soc, 5:530-5.

Mahler DA, Donohue JF, Barbee RA, et al. 1999. Efficacy of salmeterol xinafoate in the treatment of COPD. Chest, 115:957-65.

Mannino DM, Buist AS. 2007. Global burden of COPD: risk factors, prevalence, and future trends. Lancet, 370:765-73.

Marchese S, Lo CD, Lo CA. 2008. Outcome and attitudes toward home tracheostomy ventilation of consecutive patients: a 10-year experience. Respir Med, 102:430-6.

McDonald CF, Blyth CM, Lazarus MD, et al. 1995. Exertional oxygen of limited benefit in patients with chronic obstructive pulmonary disease and mild hypoxemia. Am J Respir Crit Care Med, 152:1616-9.

Meecham Jones DJ, Paul EA, Jones PW, et al. 1995. Nasal pressure support ventilation plus oxygen compared with oxygen therapy alone in hypercapnic COPD. Am J Respir Crit Care Med, 152:538-44.

Mehta S, Hill NS. 2001. Noninvasive ventilation. Am J Respir Crit Care Med, 163:540-77.

Melsom MN, Flatebo T, Nicolaysen G. 2007. Low concentrations of inhaled nitric oxide do not improve oxygenation in patients with very severe chronic obstructive pulmonary disease. Acta Anaesthesiol Scand, 51:559-64.

Menezes AM, Perez-Padilla R, Jardim JR, et al. 2005. Chronic obstructive pulmonary disease in five Latin American cities (the PLATINO study): a prevalence study. Lancet, 366:1875-81.

Moloney ED, Kiely JL, McNicholas WT. 2001. Controlled oxygen therapy and carbon dioxide retention during exacerbations of chronic obstructive pulmonary disease. Lancet, 357:526-8.

MRC. 1981. Long term domiciliary oxygen therapy in chronic hypoxic cor pulmonale complicating chronic bronchitis and emphysema. Report of the Medical Research Council Working Party. Lancet, 1:681-6.

Nava S, Ambrosino N, Clini E, et al. 1998. Noninvasive mechanical ventilation in the weaning of patients with respiratory failure due to chronic obstructive pulmonary disease. A randomized, controlled trial. Ann Intern Med, 128:721-8.

Nava S, Ambrosino N, Rubini F, et al. 1993. Effect of nasal pressure support ventilation and external PEEP on diaphragmatic activity in patients with severe stable COPD. Chest, 103:143-50.

Nava S, Ceriana P. 2004. Causes of failure of noninvasive mechanical ventilation. Respir Care, 49:295-303.

Nava S, Gregoretti C, Fanfulla F, et al. 2005. Noninvasive ventilation to prevent respiratory failure after extubation in high-risk patients. Crit Care Med, 33:2465-70.

Niewoehner DE, Erbland ML, Deupree RH, et al. 1999. Effect of systemic glucocorticoids on exacerbations of chronic obstructive pulmonary disease. Department of Veterans Affairs Cooperative Study Group. N Engl J Med, 340:1941-7.

Niewoehner DE, Rice K, Cote C, et al. 2005. Prevention of exacerbations of chronic obstructive pulmonary disease with tiotropium, a once-daily inhaled anticholinergic bronchodilator: a randomized trial. Ann Intern Med, 143:317-26.

Nonoyama ML, Brooks D, Guyatt GH, et al. 2007. Effect of oxygen on health quality of life in patients with chronic obstructive pulmonary disease with transient exertional hypoxemia. Am J Respir Crit Care Med, 176:343-9.

NOTT. 1980. Continuous or nocturnal oxygen therapy in hypoxemic chronic obstructive lung disease: a clinical trial. Nocturnal Oxygen Therapy Trial Group. Ann Intern Med, 93:391-8.

O’Donnell DE, Banzett RB, Carrieri-Kohlman V, et al. 2007. Pathophysiology of dyspnea in chronic obstructive pulmonary disease: a roundtable. Proc Am Thorac Soc, 4:145-68.
O’Donnell DE, Revill SM, Webb KA. 2001. Dynamic hyperinflation and exercise intolerance in chronic obstructive pulmonary disease. Am J Respir Crit Care Med, 164:770-7.

O'Reilly P, Bailey W. 2007. Long-term continuous oxygen treatment in chronic obstructive pulmonary disease: proper use, benefits and unresolved issues. Curr Opin Pulm Med, 13:120-4.

Oswald-Mammosser M, Weitzenblum E, Quoix E, et al. 1995. Prognostic factors in COPD patients receiving long-term oxygen therapy. Importance of pulmonary artery pressure. Chest, 107:1193-8.

Perrin C, El Far Y, Vandenbos F, et al. 1997. Domiciliary nasal intermittent positive pressure ventilation in severe COPD: effects on lung function and quality of life. Eur Respir J, 10:2835-9.

Peter JV, Moran JL, Phillips-Hughes J, et al. 2002. Noninvasive ventilation in acute respiratory failure - a meta-analysis update. Crit Care Med, 30:555-62.

Pfeifer M. 2007. [Invasive ventilation]. Dtsch Med Wochenschr, 132:492-6.

Phua J, Kong K, Lee KH, et al. 2005. Noninvasive ventilation in hypercapnic acute respiratory failure due to chronic obstructive pulmonary disease vs other conditions: effectiveness and predictors of failure. Intensive Care Med, 31:533-9.

Pinto-Plata VM, Cote C, Cabral H, et al. 2004. The 6-min walk distance: change over time and value as a predictor of survival in severe COPD Eur Respir J, 23:28-33.

Plant PK, Elliott MW. 2003. Chronic obstructive pulmonary disease *9: management of ventilatory failure in COPD. Thorax, 58:537-42.

Plant PK, Owen JL, Elliott MW. 2000. One year period prevalence study of respiratory acidosis in acute exacerbations of COPD: implications for the provision of non-invasive ventilation and oxygen administration. Thorax, 55:550-4

Plant PK, Owen JL, Elliott MW. 2001. Non-invasive ventilation in acute exacerbations of chronic obstructive pulmonary disease: long term survival and predictors of in-hospital outcome. Thorax, 56:708-12.

Quinnell TG, Pilsworth S, Shneerson JM, et al. 2006. Prolonged invasive ventilation following acute ventilatory failure in COPD: weaning results, survival, and the role of noninvasive ventilation. Chest, 129:133-9.

Rabe KF, Hurd S, Anzueto A, et al. 2007. Global strategy for the diagnosis, management, and prevention of chronic obstructive pulmonary disease: GOLD executive summary. Am J Respir Crit Care Med, 176:532-55

Ram FS, Picot J, Lightowler J, et al. 2004. Non-invasive positive pressure ventilation for treatment of respiratory failure due to exacerbations of chronic obstructive pulmonary disease. Cochrane Database Syst Rev, CD004104.

Renston JP, DiMarco AF, Supinski GS. 1994. Respiratory muscle rest using nasal BiPAP ventilation in patients with stable severe COPD Chest, 105:1053-60.

Ringbaek TJ, Viskum K, Lange P. 2002. Does long-term oxygen therapy reduce hospitalisation in hypoxaemic chronic obstructive pulmonary disease? Eur Respir J, 20:38-42.

Robinson TD, Freiberg DB, Regnis JA, et al. 2000. The role of hypoventilation and ventilation-perfusion redistribution in oxygen-induced hypercapnia during acute exacerbations of chronic obstructive pulmonary disease. Am J Respir Crit Care Med, 161:1524-9.

Roussos C, Koutsoukou A. 2003. Respiratory failure. Eur Respir J Suppl, $47: 3 \mathrm{~s}-14 \mathrm{~s}$

Scala R, Nava S, Conti G, et al. 2007. Noninvasive versus conventional ventilation to treat hypercapnic encephalopathy in chronic obstructive pulmonary disease. Intensive Care Med, 33:2101-8.

Schonhofer B, Dellweg D, Suchi S, et al. 2007. Exercise Endurance before and after Long-Term Noninvasive Ventilation in Patients with Chronic Respiratory Failure. Respiration.

Schonhofer B, Euteneuer S, Nava S, et al. 2002. Survival of mechanically ventilated patients admitted to a specialised weaning centre. Intensive Care Med, 28:908-16.

Schumaker GL, Epstein SK. 2004. Managing acute respiratory failure during exacerbation of chronic obstructive pulmonary disease. Respir Care, 49:766-82. 
Seneff MG, Wagner DP, Wagner RP, et al. 1995. Hospital and 1-year survival of patients admitted to intensive care units with acute exacerbation of chronic obstructive pulmonary disease. JAMA, 274:1852-7.

Sivasothy P, Smith IE, Shneerson JM. 1998. Mask intermittent positive pressure ventilation in chronic hypercapnic respiratory failure due to chronic obstructive pulmonary disease. Eur Respir J, 11:34-40.

Smith TC, Marini JJ. 1988. Impact of PEEP on lung mechanics and work of breathing in severe airflow obstruction. J Appl Physiol, 65:1488-99

Strumpf DA, Millman RP, Carlisle CC, et al. 1991. Nocturnal positivepressure ventilation via nasal mask in patients with severe chronic obstructive pulmonary disease. Am Rev Respir Dis, 144:1234-9.

Swinburn CR, Mould H, Stone TN, et al. 1991. Symptomatic benefit of supplemental oxygen in hypoxemic patients with chronic lung disease. Am Rev Respir Dis, 143:913-5.

Tremblay LN, Slutsky AS. 2006. Ventilator-induced lung injury: from the bench to the bedside. Intensive Care Med, 32:24-33.

Tuggey JM, Plant PK, Elliott MW. 2003. Domiciliary non-invasive ventilation for recurrent acidotic exacerbations of COPD: an economic analysis. Thorax, 58:867-71.
Wanger JS, Ikle DN, Cherniack RM. 1996. The effect of inspiratory maneuvers on expiratory flow rates in health and asthma: influence of lung elastic recoil. Am J Respir Crit Care Med, 153:1302-8.

Ward NS, Dushay KM. 2008. Clinical concise review: Mechanical ventilation of patients with chronic obstructive pulmonary disease. Crit Care Med, 36:1614-9.

Windisch W. 2008. Impact of home mechanical ventilation on health-related quality of life. Eur Respir J, 32:1328-36.

Windisch W, Budweiser S, Heinemann F, et al. 2008. The Severe Respiratory Insufficiency Questionnaire was valid for COPD patients with severe chronic respiratory failure. J Clin Epidemiol, 61:848-53.

Windisch W, Kostic S, Dreher M, et al. 2005. Outcome of patients with stable COPD receiving controlled noninvasive positive pressure ventilation aimed at a maximal reduction of $\mathrm{Pa}\left(\mathrm{CO}_{2}\right)$. Chest, 128:657-62.

Wongsurakiat P, Maranetra KN, Wasi C, et al. 2004. Acute respiratory illness in patients with COPD and the effectiveness of influenza vaccination: a randomized controlled study. Chest, 125:2011-20.

Zielinski J, Tobiasz M, Hawrylkiewicz I, et al. 1998. Effects of long-term oxygen therapy on pulmonary hemodynamics in COPD patients: a 6-year prospective study. Chest, 113:65-70. 